\title{
O Uso do Potencial Fitogeográfico pelas Comunidades Tradicionais em Indiaroba-SE
}

\author{
The Use of Potential Fitogeográfico by Traditional Communities in Indiaroba-SE
}

\author{
Silva $^{1}$, M. S. F.; Almeida ${ }^{2}$, G. L. \\ ms.ferreira.s@hotmail.com
}

\begin{abstract}
Resumo
Essa pesquisa visa analisar o potencial fitogeográfico utilizado pelas comunidades tradicionais nos povoados Pontal, Murioca, Convento, Terra Caída, Preguiça de Cima e Preguiça de Baixo em Indiaroba/SE. A pesquisa foi feita a partir de levantamento bibliográfico, pesquisa de campo, entrevistas com roteiro semiestruturado com presidente de associação e da Colônia Z4 e membros das comunidades tradicionais (catadoras de mangaba, pescadores artesanais e marisqueiras). $\mathrm{O}$ potencial fitogeográfico está representado pelos fragmentos de restinga, manguezais, vegetação secundária, floresta ombrófila densa, campos de várzea e vegetação de dunas e encontra-se ameaçado em função das atividades turística e agropecuária, o que tem implicado em impactos socioambientais que afetam as práticas extrativistas e o modo de vida dessas comunidades. Ademais, o acesso aos territórios que resguardam potencial fitogeográfico tem sido restrito e/ou impedido pelos proprietários de terras. Há necessidade de medidas mitigadoras que coíbam os impactos das atividades que comprometem a biodiversidade. As estratégias para gestão ambiental devem priorizar a criação de corredores ecológicos de Mata Atlântica, evitando que a vegetação seja suprimida, além de possibilitar a permanência das atividades extrativistas, a partir do uso do potencial fitogeográfico, de modo que possa conservar os saberes ambientais e melhorar a qualidade de vida das comunidades tradicionais.
\end{abstract}

Palavras-chave: Atividades Extrativistas, Território e Saberes Ambientais.

\begin{abstract}
This research aims to analyze the potential fitogeográfico used by traditional communities in the villages Pontal, Murioca, Convent, Land Sag Sloth Sloth Up and Down in Indiaroba / SE. The survey was conducted from literature, field research, interviews with semi-structured with President of the association and the Cologne Z4 and members of traditional communities (pickers mangaba, artisanal fishermen and seafood restaurants). The fitogeográfico potential is represented by the sandbank fragments, mangroves, secondary vegetation, dense forest, lowland fields and vegetation of dunes and is threatened due to the tourist activities and agriculture, which has been implicated in social and environmental impacts that affect practices extractive and the way of life of these communities. In addition, access to territories that protect fitogeográfico potential has been restricted and/or prevented by landowners. There is need for mitigation measures that restrain the impacts of activities that compromise biodiversity. Strategies for environmental management must prioritize the creation of ecological corridors of Atlantic, preventing the vegetation is removed, and enable the persistence of extractive activities, from the use of fitogeográfico potential, so that it can retain the environmental knowledge and improve the quality of life of traditional communities.
\end{abstract}

Keywords: Extractive Activities, Planning and Environmental Knowledge.

\section{INTRODUÇÃO}

O Brasil é um dos países que está no ranking dos países que apresenta maior potencial no que se refere à biodiversidade (DRUMMOND e ANTONINI, 2006). Mas, desde o período de colonização suas florestas vêm sendo sistematicamente destruídas. Embora a importância que os países denominados megadiversos, dentre eles o Brasil, apresentam em relação ao potencial de recursos naturais, boa parte de suas florestas continua sendo substituídas pelas mais diversas atividades. Essa 
situação tem implicado na perda da biodiversidade e, consequentemente, afeta o modo de vida das comunidades tradicionais que utilizam esses recursos para sua sobrevivência.

A questão do potencial fitogeográfico está vinculada aos espaços que detém biodiversidade, tanto para atender as necessidades do presente como também reservados para usos futuros. Porém, esse potencial não abrange apenas à proteção dos recursos naturais, pois engloba os interesses e as condições de vida dos atores sociais que dependem direta ou indiretamente da conservação desses recursos. Assim:

Para a compreensão do conceito de potencial fitogeográfico é necessário retomar o conceito de recursos naturais que são componentes da paisagem geográfica, materiais ou não, que ainda não foram fortemente modificados pelo trabalho humano e cuja própria gênese independe do homem, mas que de alguma forma foram-lhes atribuídos, historicamente, valores econômicos, sociais e culturais (SILVA, 2012, p. 133).

Nesse contexto, as Unidades de Conservação (UCs) são territórios que dispõe de potencial fitogeográfico que podem ser usados de forma direta ou indireta pelas comunidades tradicionais e pequenos produtores locais. Entretanto, essas unidades, embora criadas para com o objetivo de conservar os recursos naturais, na prática nem sempre são espaços conservados em função de diversos atores envolvidos com os mais variados interesses. Para conservar o potencial fitogeográfico é preciso pensar nas dimensões de sustentabilidade desses territórios considerando a inter-relação dos elementos biofísicos. Oliveira (2004) ressalta que para que seja alcançada gradativamente, é necessário o desenvolvimento de várias dimensões que se combinam, interpretam-se, integram-se, e inter-relacionam-se, a saber: social, econômica, ecológica/ambiental, cultural, demográfica, ecológica/ambiental, demográfica, política e institucional. Nas análises de Leff (2005)

A sustentabilidade ecológica aparece assim como um critério normativo para a reconstrução da ordem econômica, como uma condição para a sobrevivência humana e um suporte para chegar a um desenvolvimento duradouro, questionando as próprias bases de produção (LEFF, 2005:15).

Para proteção da biodiversidade não basta apenas criar Áreas Protegidas, implica também na utilização dos saberes ambientais e das formas de manejo usadas pelas comunidades tradicionais. Nesse aspecto, Castro (2000) considera que as atividades produtivas contêm e combinam formas materiais e simbólicas com as quais os grupos humanos agem sobre determinado recorte territorial.

Neste cenário, há diversas possibilidades de manejo dos recursos naturais a serem extraídos, principalmente para o aproveitamento múltiplo dos territórios com potencial fitogeográfico, como floresta tropical, através da utilização de práticas de manejo adequadas usadas por essas populações, permitindo assim, a regeneração seletiva de seus recursos naturais e o cultivo de produtos diversificados em consonância com a conservação ambiental. 
As UCs constituem espaços territoriais que apresentam características relevantes, onde a depender da categoria, há o envolvimento de comunidades tradicionais que extraem os recursos da natureza de forma sustentável, como por exemplo, as categorias de Uso Sustentável. Esses espaços são de grande relevância para proteção tanto do potencial fitogeográfico como do modo de vida das comunidades tradicionais. No SNUC, as comunidades tradicionais são definidas como:

Grupos humanos culturalmente diferenciados, vivendo há, no mínimo, três gerações em um determinado ecossistema, historicamente reproduzindo seu modo de vida, em estreita dependência do meio natural para sua subsistência e utilizando os recursos naturais de forma sustentável (BRASIL, 2000).

Em Sergipe as catadoras de mangaba foram reconhecidas enquanto comunidades tradicionais, pela a Lei Estadual 7.082 de dezembro de 2010, sendo denominadas como um:

Grupo culturalmente diferenciado, que devem ser protegidas segundo as suas formas próprias de organização social, seus territórios e recursos naturais, indispensáveis para a garantia de sua reprodução física, cultural, social, religiosa e econômica (SERGIPE, 2010).

Essas comunidades extrativistas comumente utilizam o potencial fitogeográfico tanto de propriedades privadas como de espaços público, como é o caso das UCs de Uso Sustentável. Esses territórios apesar de serem dotados de potencial fitogeográfico também são palco de conflitos entre os diversos atores que se apropriam, controlam e usam os recursos naturais.

As UCs são criadas por força da lei e constituídas por práticas e instituições regulatórias criadas e mantidas por indivíduos ou grupos sociais e legitimadas pelo Poder Público. Nesse processo de consolidação dos "territórios da conservação", os atores sociais envolvidos enfrentam uma diversidade de conflitos aflorados, como a superposição de territórios de vida, [territórios do cotidiano], de trabalho, de especulação e de esperança" (COELHO, CUNHA e MONTEIRO, 2009).

Há UCs que há conflitos entre as comunidades tradicionais, que utilizam os recursos naturais para sua sobrevivência, através de suas práticas extrativistas; fazendeiros, empresários e outros atores ligados às atividades turísticas que provocam impactos socioambientais os quais refletem diretamente no modo de vida dessas comunidades.

Em Sergipe, ao longo do tempo a paisagem natural foi sendo substituída pelos cultivos de coco e mais recentemente é notória a instalação de empreendimentos imobiliários em locais inadequados, como por exemplo, nas áreas de manguezais e margens de rios, onde a vegetação nativa foi retirada e, consequentemente, provocou impactos socioambientais que refletem diretamente no modo de vida das comunidades tradicionais e, consequentemente, desencadeando conflitos face a apropriação, controle e uso dos territórios que possuem potencial fitogeográfico.

A referida pesquisa foi realizada na Área de Proteção Ambiental (APA) do Litoral Sul de Sergipe, uma UC de Uso Sustentável, especialmente nos povoados: Convento, Pontal, Murioca, 
Terra Caída, Preguiça de Baixo e Preguiça de Cima, localizados no município de Indiaroba, cujo potencial fitogeográfico vem sendo utilizado pelas comunidades tradicionais e ameaçado em função de outros usos estabelecidos que colocam em risco a base de sustento dessas comunidades.

A criação da APA no Litoral Sul de Sergipe tem como objetivo possibilitar o equilíbrio entre o uso de forma sustentável dos recursos naturais e a conservação do ambiente, visando melhorias na qualidade de vida das comunidades envolvidas. Todavia, no recorte empírico as comunidades nem sempre tem acesso ao potencial fitogeográfico para realização de suas práticas extrativistas, como por exemplo, aos manguezais e as áreas de restinga, de onde retiram o sustento da família.

Esse potencial está representado pelos fragmentos de restingas, manguezais e vegetação secundária, utilizados direta ou indiretamente por essas comunidades. Vale ressaltar a importância dessa vegetação em Indiaroba devido sua relevância para conservação dos recursos hídricos, também considerado como fonte de subsistência para os pescadores artesanais.

Nos povoados pesquisados destaca-se a vegetação de restinga utilizada para a coleta da mangaba (Hancornia speciosa) e demais frutos, tais como: murici (Byrsonima crassifólia), goiaba (Psidium guajava), caju (Anacardium occidentale), cambucá (Plinia edulis), dentre outras. Ademais, há também o uso dos ecossistemas de manguezais que propiciam a coleta de mariscos e crustáceos; além dos cursos fluviais utilizados para a prática da pesca artesanal. A permanência desses ambientes depende da conservação do potencial fitogeográfico. Há necessidade de planejamento e gestão ambiental a partir da elaboração e implementação de zoneamento ecológico econômico, pois o potencial vem sendo ameaçado em função do avanço das atividades incompatíveis com a conservação ambiental.

\section{METODOLOGIA}

Para o desenvolvimento dessa pesquisa foram realizadas as seguintes etapas: levantamento bibliográfico e documental; pesquisa de campo; mapeamento; tabulação; ordenamento dos dados; e, análise e interpretação das informações obtidas.

O levantamento bibliográfico ocorreu a partir de leituras em livros, artigos científicos e teses que tratavam de recursos naturais, Unidades de Conservação, biodiversidade e potencial fitogeográfico. No caso do levantamento documental foram consultados os instrumentos legais norteadores da política de conservação ambiental, tais como: Sistema Nacional de Unidades de Conservação (SNUC), Utilização e Proteção da Vegetação da Mata Atlântica e o Plano Nacional de Áreas Protegidas (PNAP). A análise desses documentos foi de extrema relevância para compreender a 
criação, gestão e implementação das UCs nacional/local e suas implicações para as comunidades tradicionais, considerando o potencial fitogeográfico existente.

A pesquisa de campo ocorreu mediante a observação sistematizada e aplicação de entrevistas com roteiro semiestruturado, diálogos informais e observações in loco nos povoados pesquisados. As entrevistas, com roteiro semiestruturado, priorizando questões abertas, foram aplicadas a representante do Movimento das Catadoras de Mangaba, da Colônia de Pescadores Z4 e com 18 membros das comunidades tradicionais (catadoras de mangaba, pescadores artesanais, marisqueiras) e pequenos produtores locais. A observação sistematizada ocorreu ao longo dos povoados de modo que pudesse identificar os fragmentos florestais existentes. Essa informação foi de suma importância, especialmente para o mapeamento, com o uso do software ArcGis 9.3, realizado a partir de ortofotocartas/2003 (SERGIPE, 2003) cujas informações foram atualizadas a partir dos trabalhos de campo. As observações de campo foram anotadas bem como o posicionamento geográfico com o uso do GPS Garmim, cujos pontos foram plotados sobre as ortofotocartas para o mapeamento do uso e cobertura do solo.

Foram realizadas 18 entrevistas, distribuídas da seguinte forma: 11 em Pontal e 7 em Terra Caída, além de vários diálogos informais realizados nos outros povoados, uma vez que haviam membros das comunidades tradicionais que optaram por uma conversa informal.

Ao término da aplicação dos instrumentos de coleta de informações, estas foram agrupadas para análise e outras receberam tratamento estatístico a fim de melhor visualizar os fenômenos abordados na pesquisa.

A análise e interpretação das informações adquiridas ao longo da pesquisa possibilitaram a análise do potencial fitogeográfico usado pelas comunidades tradicionais nos povoados pesquisados, bem como os entraves que ameaçam e/ou impedem o uso dos recursos naturais por essas comunidades nos referidos povoados pesquisados.

\section{RESULTADOS E DISCUSSÃO}

No tocante a fitogeografia, o município de Indiaroba apresenta os seguintes tipos de vegetação: pequenos fragmentos de floresta ombrófila densa, manguezais, vegetação de restinga, vegetação secundária e vegetação de dunas ${ }^{1}$. Essa vegetação representa o potencial fitogeográfico na zona rural desse município que faz parte da APA do Litoral Sul de Sergipe.

Entretanto, as práticas de cultivos agrícolas, aquicultura (carcinicultura), pastagens e atividades ligadas ao turismo vêm contribuindo para redução desses fragmentos, uma vez que os dejetos que 
são produzidos nas atividades de carcinicultura são lançados diretamente nos cursos d'água, contribuindo para a redução dos peixes e mariscos. Por outro lado, a conservação desses fragmentos é de singular importância para a manutenção dos fatores biofísicos: geomorfologia, pedologia, geologia, fauna, hidrografia, além da relevância para manter o modo de vida das comunidades tradicionais.

Na APA do Litoral Sul de Sergipe, mais precisamente nos povoados pesquisados em Indiaroba, o potencial fitogeográfico está representado pela floresta ombrófila densa, associação secundária, fragmentos de restinga, vegetação de mangue e vegetação de dunas (Figura 01), cujos fragmentos são utilizados pelas comunidades tradicionais para realização de suas práticas extrativistas. Essas comunidades buscam outras localidades fora do município para realizar suas práticas extrativistas em função dos impactos socioambientais provocados pelas atividades turística e agropecuária, como por exemplo, o aterro das áreas de manguezais e o desmatamento das áreas de restinga.

A APA do Litoral Sul de Sergipe caracteriza-se por apresentar uma dinâmica de atividades desenvolvidas pelas comunidades tradicionais, as quais se deslocam em busca de territórios que possam desenvolver suas práticas predominantes, tais como: a catação de mangaba, a pesca artesanal e a mariscagem, que garantem a sobrevivência. No passado para o desenvolvimento dessas atividades, essas comunidades estabeleciam uma divisão do trabalho, na qual a coleta da mangaba era realizada, principalmente pelas mulheres; a pesca artesanal e a mariscagem pelos homens. Todavia, atualmente, tanto as mulheres como os homens atuam na pesca artesanal, na mariscagem, na coleta da mangaba e vice-versa. Vale ressaltar, que quando os homens não estão pescando ajudam a coletar mangaba, no entanto, não participam da comercialização da mangaba, conforme relatou o Ator 01:

"Nós íamos só catar mangaba e os homens vão pescar, mas hoje em dia pescamos com os homens e eles catam mangaba com nós também" (Ator 01, 2014).

Nas áreas de restinga, as comunidades tradicionais coletam a mangaba nos povoados Murioca, Convento, Preguiça de Cima e Preguiça de Baixo, pois nas proximidades desses povoados não há cursos d'água. Já nos povoados Pontal e Terra Caída, apresentam cursos d'água, onde as comunidades extraem os produtos dos rios e manguezais. Ademais, é comum a saída das dessas comunidades para realização das atividades extrativistas em outros municípios que possuem potencial para pesca artesanal, coleta de mangaba e mariscagem. Nesse sentido, optou por deixar no mapa de uso e cobertura (Figura 01 e 02) o recorte da APA do Litoral Sul de Sergipe.

\footnotetext{
${ }^{1}$ A vegetação foi identificada com base nos trabalhos de campo.
} 


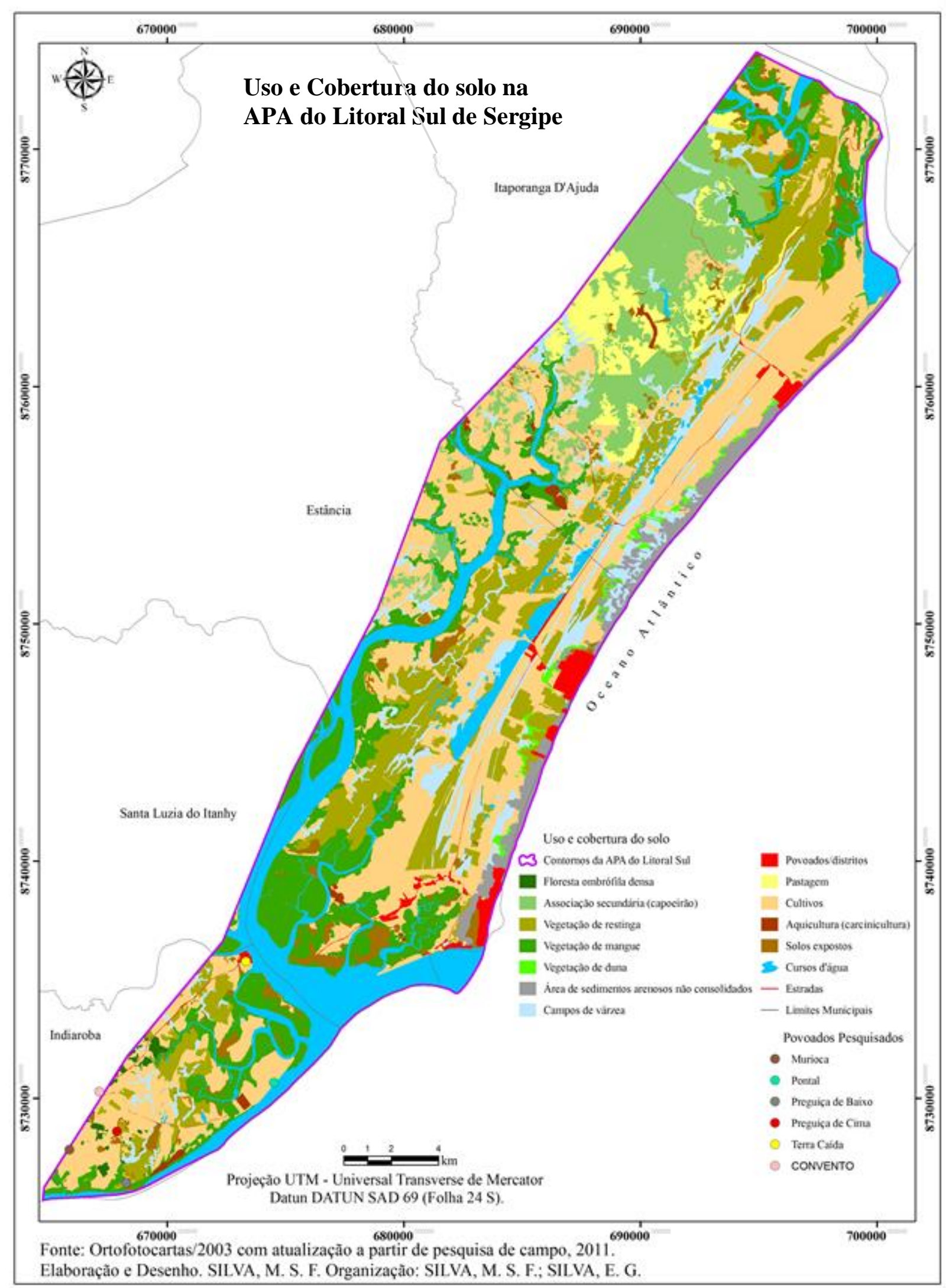

Figura 01: Uso e cobertura do solo na APA do Litoral Sul de Sergipe. 


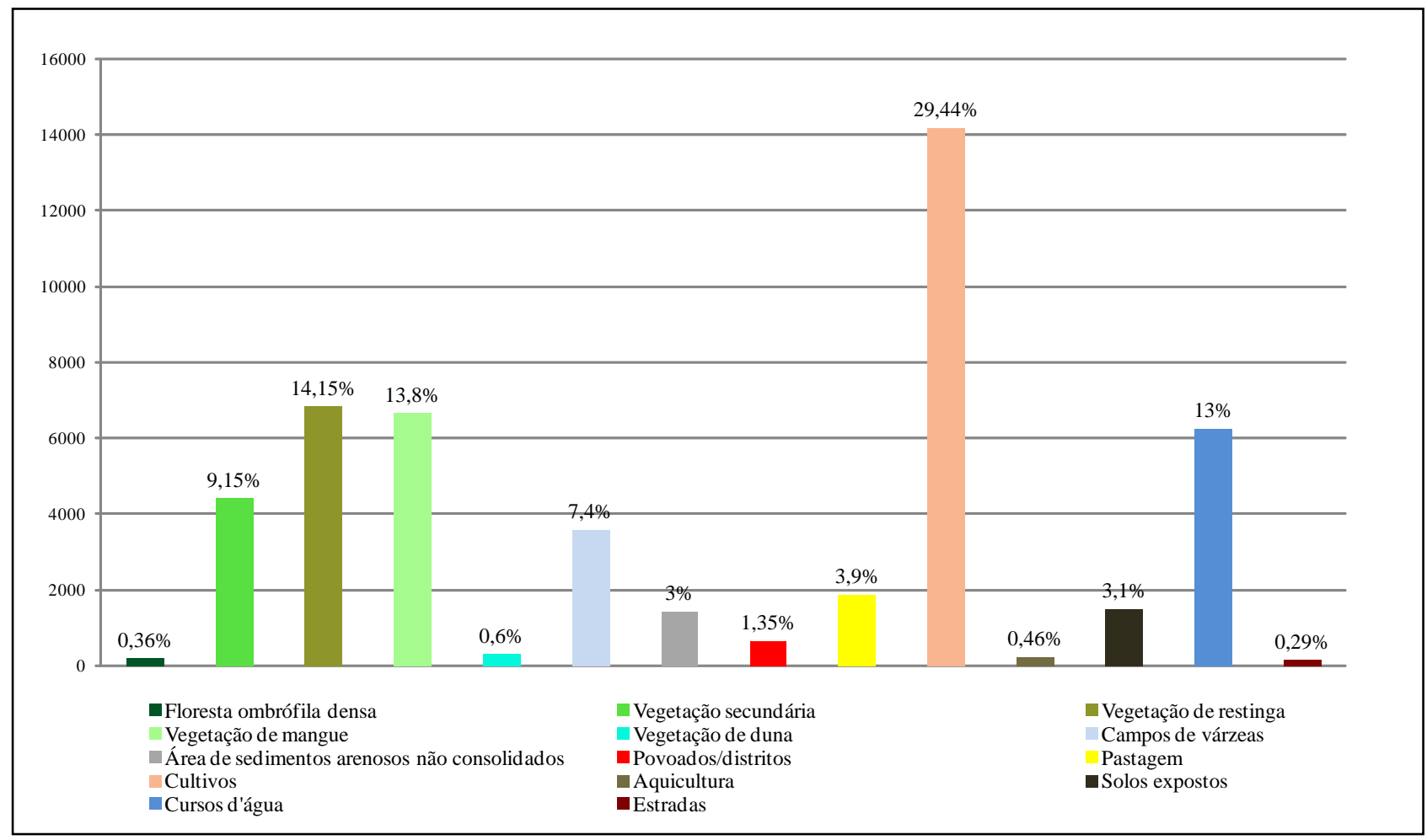

Fonte: SERGIPE: Ortofotocartas/2003 com atualização a partir de pesquisa de campo Elaboração e Organização: SILVA, M. S. F.; SILVA, E. G.

Figura 02: Uso e cobertura do solo na APA Litoral Sul

A Hancornia speciosa (mangaba) é uma planta nativa, de caráter sazonal onde, na maioria das vezes, as catadoras não possuem terra para coletar a fruta, obtendo a mesma em terras consideradas “devolutas" e nas áreas privadas quando é permitida a entrada pelo proprietário. Em outras fazendas, os proprietários delimitam seu território com cercas justamente para impedir o acesso das catadoras. Ademais, há constantemente, no período de safra da fruta (verão), o deslocamento das comunidades para os povoados vizinhos de Indiaroba para coletar a mangaba.

Nos povoados Pontal e Terra Caída, além dos outros povoados pesquisados os conflitos eclodem em função das fazendas, que impedem tal acesso para coleta da fruta. Assim, como os frutos não são utilizados pelos proprietários das áreas, há relatos da retirada das espécies de mangabeiras para que as catadoras não retornem a essa área.

O principal instrumento utilizado na coleta da mangaba são os baldes, no qual a partir da fruta coletada, ocorre uma seleção para verificar as que estão machucadas ou não. Ou seja, as que apresentam um bom estado de conservação são destinadas para a venda, enquanto que as demais são direcionadas para outros fins, como por exemplo, na fabricação de licor. Tanto a mangaba in natura como os seus derivados são armazenados em freezers. Nesse sentido, o Ator 02 afirma que:

"Da mangaba não se perde nada” (Ator 02, 2014). 
Dentre as principais dificuldades enfrentadas pelas catadoras de mangaba no tocante a atividade extrativista está à falta de propriedade da terra, onde $78 \%$ dos entrevistados não possuem posse da terra, fazendo com que essas comunidades se desloquem para outras áreas, como por exemplo, para o município de Conde, no estado da Bahia. Além disso, outro fator que contribuiu para esse deslocamento é que os proprietários dos sítios privados cortam as espécies de mangabeiras.

Ademais, o desmatamento das áreas de restinga impede a coleta da mangaba, pois essas áreas vêm sendo utilizadas para a implantação de empreendimentos ligados a atividade turística. Apenas $22 \%$ possuem pequenos sítios para a realização da coleta da mangaba livremente e de outros cultivos como milho, feijão, macaxeira, coco e ameixa amarela.

A partir da mangaba in natura são produzidos derivados diversos como bolinhos, tortas, biscoito, geleia, balas, dentre outros, os quais alguns desses derivados são vendidos para as escolas para a merenda escolar, através de uma parceria entre o poder público municipal e as catadoras, enquanto os outros produtos são destinados para as feiras livres nos municípios de Estância e Aracaju.

Quando outras comunidades locais não possuem os instrumentos necessários para produzir os derivados da mangaba, é comum as que possuem emprestarem seus equipamentos visando estimular o fortalecimento dessa atividade. Nesse aspecto, o Ator 03 ressalta que:

"Aqui nós emprestamos o que é necessário para aquelas comunidades que não possuem para que elas possam também produzir os derivados da mangaba" (Ator 03, 2014).

A pesca artesanal é outra atividade realizada pelas comunidades tradicionais nos povoados pesquisados. É praticada principalmente em Terra Caída e tem como principais espécies coletadas a Lucina pectinata (lambreta) e Thalassophryne nattereri (niquim), Mugil cephalus (tainha), Sardinella brasiliensis (sardinha), Centropomus undecimalis (robalo), Luciopimelodus platanus (bagre), encontrados tanto nos cursos fluviais quanto na maré. Para a obtenção desses produtos, são necessários instrumentos de coleta, a saber: rede, tarrafa, vara, barco, dentre outros. Os pescadores entre si, diferentemente das catadoras, não compartilham os instrumentos que são utilizados em suas atividades, dificultando, assim, a coleta do produto.

Embora sejam dotadas de saberes ambientais, passados de geração a geração, quando foram questionados se fazem parte de alguma comunidade tradicional, todos os entrevistados afirmaram que não fazem parte de nenhuma comunidade tradicional. Ademais, mesmo que já tenham ouvido falar, não compreendem nada a respeito do termo, nem tampouco o termo RESEX. Nos diálogos são evidentes seus saberes, como ressalta o Ator 04:

"Nossos pais ensinou a consertar as coisas que precisamos para pescar ou catar mangaba" (Ator 04, 2014). 
Dentre as espécies coletadas nos manguezais correspondentes a atividade marisqueira, destacase: Ucides cordatus (caranguejo), Mytella charruana (sururu), Aratus pisoni (aratu), massumi, Litopenaeus vannamei (camarão), Tridacna costata (ostra), Callinectes danae (siri) e Cardisoma guanhumi (guaiamu). Há uma dinâmica na variação do pescado nas épocas de coleta: no inverno, a coleta dos mariscos diminui, mas o preço aumenta em função da dificuldade de oferta, enquanto que no verão a coleta aumenta, mas o preço diminui. O Ator 05 relatou que:

"Quando não coletamos peixes e mariscos, vamos coletar mangaba" (Ator 05, 2014).

Os produtos oriundos da pesca artesanal apresentam dois destinos: parte é destinada para a alimentação da família e a outra é armazenada em geladeiras para ser comercializada com os cambistas os quais visitam as comunidades semanalmente, adquirindo os produtos por um valor a baixo do mercado local.

Embora a atividade turística seja bastante expressiva no Litoral Sul de Sergipe e provoque impactos socioambientais afetando diretamente o modo de vida das comunidades, para os entrevistados o turismo representa um ponto positivo para a comercialização dos produtos coletados, como afirmou o Ator 06:

"Com o turismo aqui na região, as vendas dos nossos produtos aumentaram" (Ator 06, 2014).

A implantação de atividades, como a carcinicultura tem provocado a diminuição de mariscos e peixes, pois os dejetos produzidos são lançados diretamente nos cursos d'água e nos manguezais. Afetando, desse modo, as atividades extrativistas como a pesca artesanal, a mariscagem e a coleta de caranguejo. Nesse aspecto, o Ator 07 relatou que:

"Os mariscos estão morrendo cada vez mais, pois estão colocando veneno no manguezal” (Ator 07, 2014).

Nos povoados pesquisados, o potencial fitogeográfico constitui a fonte de subsistência dos membros das comunidades tradicionais, pois são dotados de saberes ambientais que ajudam na conservação dos recursos naturais necessários para sua sobrevivência, além de nortear suas práticas extrativistas.

\section{CONSIDERAÇÕES FINAIS}

No município de Indiaroba o potencial fitogeográfico representado pelos fragmentos de floresta ombrófila densa, vegetação secundária, fragmentos de restinga, manguezais e campus de várzea asseguram direta ou indiretamente o modo de vida das comunidades tradicionais. Entretanto, esse potencial vem sendo ameaçado, devido aos usos incompatíveis com a conservação ambiental. 
Nesse sentido, em função das atividades realizadas pelos atores sociais, a quantidade de peixes e mariscos encontra-se bastante reduzida se comparada ao passado, devido à contaminação dos recursos hídricos face à disposição inadequada de resíduos sólidos e efluentes domésticos; da instalação de viveiros de camarão em áreas de manguezais, cujos dejetos são depositados nos cursos d'água, fatores estes que comprometem a biodiversidade e compromete as atividades extrativistas.

Dessa forma, é necessário à criação e implementação de mecanismos ligados a gestão ambiental, como por exemplo, o plano de gestão e de manejo, zoneamento-ecológico-econômico, os quais ainda não foram criados. Ademais, é preciso disciplinar o uso do solo, coibir o desmatamento ilegal das formações vegetais, e desenvolver estratégias no intuito de assegurar a extração dos produtos locais.

No contexto da conservação do potencial fitogeográfico e das práticas extrativistas, vários desafios devem ser enfrentados, para que de fato possa pensar na gestão ambiental que contemple conservação do potencial ainda existente, tais como: criação e implementação de outras Unidades de Conservação, pois a categoria APA não tem sido eficiente para conservação ambiental. $\mathrm{O}$ Zoneamento-Ecológico-Econômico precisa incluir estratégias de monitoramento dos fragmentos florestais de modo que possa aumentar o tamanho e melhorar as formas dessas manchas. Ademais, as propostas de corredores ecológicos de Mata Atlântica também devem ser priorizadas de modo que possibilite a troca de material genético entre as espécies.

Há também necessidade de medidas capazes de promover o fortalecimento das associações e colônia de pescadores; participação e interação das comunidades nos programas desenvolvidos pelo poder público municipal, especialmente aqueles ligados à educação, habitação, através do programa "Minha Casa, Minha Vida" e saneamento básico (tratamento de água e de efluentes domésticos, coleta regular de resíduos sólidos) visando melhorar a qualidade de vida das comunidades; ações de divulgação e valorização dos produtos extrativistas; aquisição dos equipamentos necessários para a coleta da mangaba, peixes e mariscos, além daqueles destinados à proteção das comunidades; fortalecimento da identidade cultural de modo que assegure a permanência dos saberes adquiridos ao longo do tempo; realização de campanhas socioeducativas ressaltando a importância de conservar os remanescentes florestais; dentre outros.

No tocante aos equipamentos necessários para a realização das atividades extrativistas, é primordial estabelecer estratégias para facilitar a aquisição e/ou doação de kit para os pescadores artesanais: colete salva vidas, extintores, barco, rede, dentre outros itens necessários.

\section{REFERÊNCIAS}


BRASIL. Lei $\mathbf{n}^{\mathbf{0}} 9.985$ de 18 de julho de 2000. Institui o Sistema Nacional de Unidades de Conservação da Natureza - SNUC. Brasília-DF, 2000.

BRASIL. Lei $\mathbf{n}^{\mathbf{0}} 7.082$ de 16 de dezembro de 2010. Reconhece as catadoras de mangaba como grupo cultural diferenciado e estabelece o auto-reconhecimento como critério do direito e dá outras providências. Brasília/DF, 2010.

CASTRO, E. Territórios, biodiversidade e saberes de populações tradicionais. In: DIEGUES, A. C. (Org). Etnoconservação: novos rumos para a proteção da natureza nos trópicos. São Paulo: Annablume, 2000. p. 165-182.

COELHO, M. C. N.; CUNHA, L. H. \& MONTEIRO, M. A. Unidades de Conservação: populações, recursos e territórios. Abordagens da Geografia e da Ecologia Política. In: GUERRA, A. J. T. \& COELHO, M. C. N. (Orgs.) Unidades de Conservação: Abordagens e características Geográficas. Rio de Janeiro: Bertrand Brasil, 2009. p. 67-111.

DRUMMOND, G. M.; ANTONINI, Y. A contribuição da Fundação Biodiversitas para implementação do artigo $7^{\circ}$ da Convenção sobre Diversidade Biológica. In: BENSUSAN, N., et al, (Orgs.) Biodiversidade: para comer, vestir ou passar no cabelo? Para mudar o mundo! São Paulo: Peirópolis, 2006. p. 31 - 48.

LEFF. H. Saber ambiental: Sustentabilidade, Racionalidade, Complexidade e Poder. $4^{\text {a }}$ Edição. Rio de Janeiro, 2005.

OLIVEIRA, I. C. E. Arquitetura e urbanismo nas cidades sustentáveis. $61^{\mathrm{a}}$ Semana Oficial da Engenharia, da Agricultura e da Agronomia. Congresso Nacional dos Profissionais. São Luíz/MA. 30 de Nov. a 04 de Dez. de 2004. p. 169-182.

SERGIPE. Ortofotocarta - 1:10.000 - Restituição Aerofotogramétrica - 1:10.000. Secretaria de Estado de Planejamento - SEPLAN. Elaborado pela Superintendência de estudos e Pesquisas SUPES, Gerência de Informações Geográficas e Cartográficas - GIGEC. DVD N 07. Cartas: 698778 a 705-811. PRODEMA/UFS, 2003.

SERGIPE. Lei n. 7.082 de 16 de dezembro de 2010. Que reconhece as catadoras de mangaba como um grupo culturalmente diferenciado e estabelece o auto-reconhecimento como critério do direito e dá outras providências. Aracaju, 2010.

SILVA, M. S. F. Território da Conservação: uma análise do potencial fitogeográfico das UCs de uso sustentável em Sergipe. Tese de Doutorado (NPGEO/UFS). São Cristóvão, 2012. 291f.

\section{AGRADECIMENTOS}

Agradecemos aos representantes e membros das comunidades tradicionais que participaram da pesquisa; a UFS pelo apoio na pesquisa de campo; ao Grupo de Pesquisa, GEOPLAN que possibilita diálogos e aprendizados a partir dos diferentes olhares dos pesquisadores; e, ao CNPq pela bolsa concedida, tornando possível a realização da pesquisa e desenvolvimento do bolsista.

Recebido em: 14/08/2016

Aceito para publicação em: 01/10/2016 